\title{
Analysis of the Influence of a Strategy-led Planning Approach on Successful Construction Project Implementation
}

\author{
James Olabode Bamindele Rotimi and Chamila D D Ramanayaka \\ School of Engineering, Auckland University of Technology, New Zealand
}

\begin{abstract}
This paper presents arguments for the development of a strategy-led approach to planning and implementation of construction projects. It takes the position that there are deficiencies in traditional planning algorithms, which make them inefficient to cope with the unique character of construction projects. Thus a combination of construction project strategies crafted from experiential knowledge (reflective practice methodologies) and traditional planning algorithms are needed for successful construction project planning and implementation. To confirm the argument, the study investigates the influence of strategies on 35 critical success factors which were identified through literature. It uses a combination of data collected through a questionnaire survey of 40 NZIOB Excellence award recipients for the period 2001 to 2011, and interviews with three subject matter experts to validate the influence of the strategy-led approach towards some selected critical success factors. A correlation analysis shows that there is a positive relationship between increasing project complexity and the use of strategies. Further, content analysis of study information collected suggests that complementary approaches herein referred to as the strategy-led approach is needed to achieve successful project outcomes.
\end{abstract}

Keywords: Construction project, planning and scheduling, strategy-led approach.

Paper type: Research article

\section{Introduction}

The development and advancement of traditional planning algorithms, such as the Critical Path Method (CPM) and Program Evaluation and Review Technique (PERT), could enhance project performance to a great extent (Long and Ohsato, 2007). Yet Belassi and Tukel (1996) emphasised that project failures could not be avoided by developing better scheduling techniques alone. There are other concerns that largely govern successful construction project delivery; for example, construction projects are significantly subjected to dynamism; design changes caused by errors or clients' emerging interests, uncertainty in resource flow and unexpected demand fluctuations, are a few issues that create instability in workflow. In such circumstances, planning algorithms are inadequate to assist construction managers to plan and implement projects successfully (Arashpour et al., 2014).

Contemporary construction management researches have diversified focus to the enhancement of sector productivity. Collaboration, which is a process reliant on data-centric activities, has been replaced by the requirements of integrative practices using knowledge-centric procedures (Beck, 2005). Consequently, more effective procurement methods, such as the Integrated Project Delivery, have evolved, facilitating the optimised adoption of modern technology into construction practices (AIA, 2007; Griloa and Jardim-Goncalves, 2011). Further, management

Copyright: Construction Economics and Building 2015. C) 2015 James Olabode Bamindele Rotimi and Chamila D D Ramanayaka. This is an Open Access article distributed under the terms of the Creative Commons Attribution 4.0 Unported (CC BY 4.0) License (https://creativecommons.org/licenses/by/4.0/), allowing third parties to copy and redistribute the material in any medium or format and to remix, transform, and build upon the material for any purpose, even commercially, provided the original work is properly cited and states its license.

Citation: Rotimi, J.O.B. and Ramanayaka, C.D.D., 2015. Analysis of the influence of a strategy-led planning approach on successful construction project implementation, Construction Economics and Building, 15(2), 13-30. DOI:

http://dx.doi.org/10.5130/AJCEB.v15i2.4282 
practices that are proven success in other fields (e.g. lean principles) were adapted to reflect construction project characteristics and applied successfully (Vilasini, Neitzert and Rotimi, 2014). Notwithstanding the essence of such developments, the efficiency of planning algorithms requires significant enhancement too (Fallah, Ashtiani and Aryanezhad, 2010).

Having identified inadequacies of planning algorithms (Zhao, You and Zuo, 2010), alternatives and advancements are suggested. Arashpour et al. (2014) suggested a mechanism based on optimal-sized capacity buffers, to minimize unstable workflow, and hence to enhance outputdemand coordination. Also, Hegazy and Menesi (2010) developed an alternative to CPM - which is known as the Critical Path Segment Method, believing that the activity platform is a rough level, and hence inadequate, for construction project planning. However, many suggestions (Fallah Ashtiani and Aryanezhad, 2010; Lu and Lam, 2008) are still based on the extensive use of mathematics, preferably frequentist statistics, and hence subjected to similar inadequacies as of traditional planning algorithms (Dias, 2002). It is empirically found that actual data related to construction project planning does not satisfy axiomatic assumptions associated with statistical procedures (Cottrell, 1999).

The inadequacies of mathematics are basically due to 'selective inattention' - i.e. little or no concern on clarifying real-world scenarios that include both quantitative and qualitative features (Schon, 2001; El-Anwar and Aziz, 2014; Wang et al., 2014). As opposed to selective inattention, knowledge of factors that are critical to project success should be complemented with reflecting in, on and for action (reflective interaction) (Kinsella, 2007) for solving problems. What kind of knowledge that is established in construction management to provide a holistic view of construction project planning and implementation and which includes factors that can or cannot be formulated through theoretical formulations? The answer seems to be in the discourse of critical success factors.

Under the discussion of critical success factors, Kumaraswamy and Chan (2002) provided credence to support that construction project implementation is a unique process that is characterised by context-dependencies. Thus, the findings on critical success factors encourage planning methodologies that could integrate the unique characteristics of construction projects. This feature of critical success strengthens past scholars' (Rand, 2000; Winch, 2010) critics emphasising the inadequacies of nomothetic planning algorithms, such as CPM and PERT within the construction industry.

Critical success factors have recognized that project managers competencies (Assaf and Al-Hejji, 2006), designer's experiences (Kumaraswamy and Chan, 1998) and the troubleshooting abilities of the project team (Belassi and Tukel, 1996) are significant. These would seem to encourage the use of tacit knowledge, which comes from personal attributes (i.e. practitioner dependent), in addition to theoretical knowledge. Whereas considering planning algorithms alone, encourages practitioners to become instrumental problem solvers via the use of theoretical formulations that are based on classical statistics (Long and Ohsato, 2007). Although there is a major contribution from these intellectual approaches, what kind of planning methodology has adequate flexibility to integrate both explicit and implicit knowledge, and hence to influence critical success factors positively? This is highlighted in construction management literature, but not fulfilled (Ramanayaka, 2013; Shim and Kim, 2011).

Kumar (2002) described how the focus of construction planning strategies is not limited to project schedules, but covers issues related to project organisation, manning and deployment, contracting, purchasing and value engineering. However, strategies are not exact rules, usually crafted heuristically after reflection on the relevant contexts and involve a risk of failure sometimes (De Wit and Meyer, 2004). Thus, scholarly suggestions to use a strategy-led approach, to influence construction project planning and implementation holistically, must be empirically proven. 
The current study introduces the strategy-led approach as a combination of construction project strategies crafted from experiential knowledge and traditional planning algorithms. The term 'strategy' is used in the context of this study, as that which has a foothold on reflective practice methodologies and assists construction planners in decision making and problem solving within the complexities, dynamisms, uncertainties and uniqueness of the construction process (Ramanayaka and Rotimi, 2011). To achieve the aim of this study, the suitability of the strategyled approach in construction project planning and implementation is evaluated by determining its influence on critical success factors. The following study objectives are developed.

1. To identify the factors critical to successful construction project planning and implementation.

2. To determine the influence of construction project strategies towards critical success factors under construction project characteristics (complexity, dynamism, uniqueness and uncertainty).

\section{Research Methodology}

This study is based on a methodological assumption that the abstract concepts (construction project characteristics) and competing views of engineering practices (for example, practitioners' understanding of their influence on strategies) associated with this study can be quantified to near accuracy by employing multiple research methods. Thus, the paradigmatic position of this study is post-positivism (Abbott, 2010), which allows for ideal objectivity during research investigations (Grant and Giddings, 2002). The use of mixed-method methodology under the paradigm selected permits a combination of both quantitative and qualitative methods (Guba and Lincoln, 2005).

As the first step, construction management literature related to both strategy and critical success factors were reviewed. Though Kumar (2002) argued that strategy has a broader focus on a wide range of construction management functions, his argument is based on interpretivism, using the case study method. Construction projects are unique from one to another. Hence without statistical generalisation using a reasonable number of projects, it is inappropriate to conclude that strategy has positive influence on critical success factors. On the other hand, if correlations are found between strategies and critical success factors, there will be no comprehension without qualitatively explaining the nature of strategies used and their difference compared to the principles of traditional planning algorithms. Thus, the use of a mixed method approach satisfies the needs for generalisation, validation and clarification of the study findings.

Critical success factors were selected from literature based on two considerations: 1) relevance to the New Zealand context, and 2) holistic representation of construction project planning and implementation. Following the review, content analysis (both deductively and inductively) was used to determine factors critical to project success found in archival award statements published in the 'Progressive Building' magazine for award winners of excellence by the New Zealand Institute of Buildings (NZIOB). Deductive analysis was the frequency counts of the award statements using the critical success factors that were found in literature. The inductive analysis was used to identify any theme in the award statements and that was not found in literature.

Consequently a questionnaire survey was administered to the construction project managers who were recipients of the Excellence awards by the NZIOB. A sample size of 69 was determined from a total of 160 NZIOB award recipients for the period 2001 to 2011, using Cochran's formula (Bartlett, Kotrlik and Higgins, 2001) for sample size determination, to achieve a 95\% confidence level. However to ensure an adequate response rate, questionnaires were administered to 130 awardees with available information on their contact locations. To complete research triangulation, an additional step taken by the study was to interview three subject matter 
experts to validate the findings from the questionnaire survey. The interview findings enabled an extension of knowledge on the practical feasibility of the strategy-led approach proposed within the study.

\section{Questionnaire Design}

The questionnaire focused on three types of variables: critical success factors, strategy and project characteristics. 35 critical success factors had been identified in literature (Ramanayaka, 2013) and were central to the questionnaire. The study participants were requested to provide an overall rating for the influence of strategies towards the selected critical success factors by using a 10 point scale, where 0 to 2 represents 'very low' influence at one end, with 8 to10 being 'very high' influence at the other end. To measure the amount of complexity, dynamism, uniqueness and uncertainty - which are significant project characteristics identified in a preliminary study (Ramanayaka, 2013). The same scale as of critical success factors was used for the project characteristics. Questions on strategy were in the form of open-ended questions.

In the questionnaire survey, project strategies were mentioned under both conceptual and implementation stages. These strategies belonged to either the main or sub-level, where the purpose of sub-strategies is to assist in the implementation of main strategy. These different stages and levels were used after analysing opinions given by 11 industry practitioners during a pilot survey (see Ramanayaka, 2013). In addition to deciding the stages and levels that strategies could be applied, the pilot survey helped in the design of an effective questionnaire based on the feedback from industry and academia (Barribeau et al., 2012). The general pre-testing concentrated on layout, adequacy of information, difficulty level, statistical issues and sequencing of the questions. A wide range of professionals was used for the pre-test (Table 1). In addition, reliability and validity pretesting was done to check accuracy through testing and pre-testing, by using two construction managers. The participants for the general pre-testing were informed that they were being used for a pilot study (protocol analysis), but the two participants used for the reliability and validity pre-testing were not given such information (de-briefing).

Table 1: Participation for the pilot surveys of the questionnaire

\begin{tabular}{lccc}
\hline Participant & No & Types of tests & $\begin{array}{c}\text { True participants of } \\
\text { the questionnaire }\end{array}$ \\
\hline $\begin{array}{l}\text { Production engineer and } \\
\text { Lean experts }\end{array}$ & 1 & Layout, difficulty, adequacy of information & No \\
\hline Construction managers & 3 & Content, wording, sequence, form, layout, difficulty, \\
& & adequacy of information & $\begin{array}{c}2-\text { Yes } \\
\text { 1-No }\end{array}$ \\
\hline Civil engineers & 1 & Layout, difficulty, adequacy of information & No \\
\hline Mechanical engineers & 1 & Layout, difficulty, adequacy of information & No \\
\hline Architects & 1 & Layout, difficulty, adequacy of information & No \\
\hline Quantity surveyors & 1 & Layout, difficulty, adequacy of information & No \\
\hline Statisticians & 1 & Adequacy of information, statistical significance & \\
\hline $\begin{array}{l}\text { Construction } \\
\text { management lecturers }\end{array}$ & 4 & Content, wording, sequence, form layout, difficulty, \\
\hline & adequacy of information, statistical significance & Yes \\
\hline Construction Managers & 2 & Reliability and validity pre-test & Reliability and validity \\
\hline
\end{tabular}

\section{Research Findings}

\section{Critical Success Factors}

Table 2 gives a summary of the content analysis carried out on 43 NZIOB award statements. The criterion used for the selection of the award statements, was access to information. Within the award statements, the most appropriate success factors, in line with those in literature (Pinto and Covin, 1989; Chan and Kumaraswamy, 1997; Assaf and Al-Hejji, 2006; Ramanayaka and 
Rotimi, 2012), were determined. Though specific attention was paid to finding more critical success factors, none emerged.

Table 2: Frequency counts of critical success factors in NZIOB award statements

\begin{tabular}{|c|c|c|}
\hline Strategy focus & Total (43) & $\%$ \\
\hline \multicolumn{3}{|l|}{ Project related } \\
\hline Setting clear objectives & 12 & 28 \\
\hline Coping with necessary variations & 22 & 51 \\
\hline Improving communication & 27 & 63 \\
\hline Speeding up decision making & 9 & 21 \\
\hline Handling unforeseen ground conditions & 1 & 2 \\
\hline Improving project schedules and plans & 26 & 60 \\
\hline Coping with legal/statutory requirements & 1 & 2 \\
\hline Effective use of technology & 27 & 63 \\
\hline Coping with site conditions (within the site) & 17 & 40 \\
\hline Ensuring monitoring and feedback system & 11 & 26 \\
\hline Better handling of design complexities & 11 & 26 \\
\hline Coping with estimation errors & 0 & 0 \\
\hline \multicolumn{3}{|l|}{ Organization related } \\
\hline Dealing with client's characteristics & 19 & 44 \\
\hline Improving project financing from client & 9 & 21 \\
\hline Ensuring contractor's cash flow & 2 & 5 \\
\hline Minimizing delays \& errors in design documents & 15 & 35 \\
\hline Improving site management and supervision & 23 & 53 \\
\hline Getting top management support & 2 & 5 \\
\hline Improving project finance from client & 7 & 16 \\
\hline Smoothly working with sub-contractors & 20 & 47 \\
\hline Developing project organizational structure & 1 & 2 \\
\hline Getting lower cadres' support & 6 & 14 \\
\hline \multicolumn{3}{|l|}{ Resource related } \\
\hline Minimizing material shortages & 7 & 16 \\
\hline Coping with material changes & 1 & 2 \\
\hline Deciding on off-site prefabrication & 8 & 19 \\
\hline Handling labour shortages & 6 & 14 \\
\hline Coping with low skill levels & 0 & 0 \\
\hline Handling plant shortages & 0 & 0 \\
\hline Coping with low efficiency of plants & 0 & 0 \\
\hline Coping with plant breakdowns & 0 & 0 \\
\hline Avoiding wrong selections of plants & 2 & 5 \\
\hline \multicolumn{3}{|l|}{ External related } \\
\hline Helping to minimize political issues (such as policy/regulatory changes) & 0 & 0 \\
\hline Helping to minimize economic issues (example: inflation) & 2 & 5 \\
\hline Helping to minimize social issues (disturbance to the surrounded community) & 11 & 26 \\
\hline Helping to minimize weather uncertainties & 4 & 9 \\
\hline
\end{tabular}

This should not be considered as an opposing argument towards the uniqueness of construction environments: the amount of contribution from each critical success factors towards achieving project success could be different from one context to another. The critical success factors are 
summarised under project related, organisational related, resource related and others. Compared to former studies, more recent scholars attempt to breakdown factors into minor hierarchies: for example, Pinto and Covin (1989) mentioned 'technical tasks' as a whole. Yet Ramanayaka and Rotimi (2012) and Assaf and Al-Hejji (2006) further broke down the same factor into the 'use of effective technologies', 'material optimization', 'effective design solutions' and 'avoid wrong selection of construction plants'. The factors highlighted in Table 2 follow the current trend.

\section{Demographic Information}

Table 3 provides the demographic data collected on the questionnaire participants and projects for which they had received Excellence awards; and interview participants. The purpose of the demographic information is to provide contextual background that the findings are based on.

There were 130 questionnaires distributed to the NZIOB awardees and after three follow-up reminders sent over a period of six weeks, the number of useful responses received was 40 . The participants of the questionnaire survey represented distinct educational levels, which include: degree or equivalent $(n=21 ; 52.5 \%)$, diploma/certificate $(n=12 ; 30 \%)$, postgraduate $(n=5$; $12.5 \%)$ and on-the-job training $(n=2 ; 5 \%)$. The questionnaire participants' industry experience was at least $11-15$ years, while $50 \%$ of them had worked for more than 20 years. $65 \%$ of the awardees had more than 10 years' experience as construction project managers. These results show a good level of qualification and experience in the construction industry, and indicate that data gathered are from reliable sources.

Table 3: Demographic information of the participants

\begin{tabular}{|c|c|c|c|}
\hline \multicolumn{4}{|c|}{ Demographic information for the questionnaire survey } \\
\hline \multicolumn{4}{|l|}{ Type of education } \\
\hline \multicolumn{2}{|l|}{ Post graduate } & 5 & 12.5 \\
\hline \multicolumn{2}{|l|}{ Degree or equivalent } & 21 & 52.5 \\
\hline \multicolumn{2}{|l|}{ Diploma/certificate } & 12 & 30.0 \\
\hline \multicolumn{2}{|l|}{ On the job training } & 2 & 5.0 \\
\hline \multicolumn{4}{|l|}{ Years of experience in the industry } \\
\hline \multicolumn{2}{|l|}{$11-15$} & 7 & 17.5 \\
\hline \multicolumn{2}{|l|}{$16-20$} & 13 & 32.5 \\
\hline \multicolumn{2}{|l|}{$>20$} & 20 & 50.0 \\
\hline \multicolumn{4}{|l|}{ Years of experience as a project manager } \\
\hline \multicolumn{2}{|l|}{$0-5$} & 2 & 5.0 \\
\hline \multicolumn{2}{|l|}{$6-10$} & 12 & 30.0 \\
\hline \multicolumn{2}{|l|}{$11-15$} & 12 & 30.0 \\
\hline \multicolumn{2}{|l|}{$16-20$} & 10 & 25.0 \\
\hline \multicolumn{2}{|l|}{$>20$} & 4 & 10.0 \\
\hline \multicolumn{4}{|c|}{ Demographic information for the interviews } \\
\hline & SME1 & SME2 & SME3 \\
\hline Highest level of education & Diploma/certificate & Degree or equivalent & Post graduate \\
\hline Years of experience in the industry & 21 & 18 & 15 \\
\hline Years of experience as a project manager & 10 & 11 & 10 \\
\hline
\end{tabular}

The main criteria used for the selection of the three interview participants (subject matter experts - SMEs) for the study is that: they must have at least 15 years of industry practice, including 10 years as construction project managers. The three SMEs interviewed belonged to one of the 
three categories of Diploma/certificate, degree or equivalent and post-graduate degree holders. This consistency was to minimise biased response on the basis of their educational qualifications (Schlomer et al., 2010).

Table 4: Descriptive statistics of strategy influence on critical success factors

\begin{tabular}{|c|c|c|c|c|c|c|}
\hline Critical success factors & Mean & Median & Mode & $25^{\text {th }}$ & $75^{\text {th }}$ & $\mathbf{M} *$ \\
\hline Better handling of design complexities & 8.7 & 9 & 9 & 8 & 10 & 9 \\
\hline Setting clear objectives & 8.9 & 9 & 9 & 8 & 9.5 & 9 \\
\hline Improving schedules and plans & 8.5 & 9 & 9 & 8 & 10 & 8.5 \\
\hline Improving communication & 8.7 & 9 & 9 & 8 & 9 & 8.5 \\
\hline Speeding up decision making & 8.7 & 9 & 9 & 8 & 9 & 8.5 \\
\hline Dealing with client characteristics & 8.4 & 9 & 8 & 8 & 9 & 8.5 \\
\hline Improving site management and supervision & 8.5 & 9 & 9 & 8 & 9 & 8.5 \\
\hline Minimising material shortages & 8.3 & 9 & 9 & 8 & 9 & 8.5 \\
\hline Coping with necessary variations & 8.2 & 9 & 9 & 7.5 & 9 & 8.5 \\
\hline Coping with site conditions (within the site) & 8.3 & 8.5 & 9 & 8 & 9 & 8.5 \\
\hline Minimising political issues & 8.3 & 8.5 & 9 & 7 & 9 & 8.5 \\
\hline Minimising delays and errors in design documents & 8.3 & 8 & 8 & 8 & 9 & 8.5 \\
\hline Smoothing work with sub-contractors & 8.4 & 8 & 8 & 8 & 9 & 8.5 \\
\hline Deciding on off-site prefabrication & 8.3 & 8 & 8 & 8 & 9 & 8.5 \\
\hline Ensuring feedback and monitoring & 8.1 & 8 & 8 & 7 & 9 & 8 \\
\hline Developing project organisational structure & 7.9 & 8 & 8 & 7 & 9 & 8 \\
\hline Coping with material changes & 8 & 8 & 9 & 7 & 9 & 8 \\
\hline Effective use of technology & 7.5 & 8 & 9 & 6 & 9 & 8 \\
\hline Getting lower cadres' support & 7.5 & 8 & 9 & 6 & 9 & 8 \\
\hline Minimising economic issues & 7.6 & 8 & 8 & 6 & 9 & 8 \\
\hline Handling labour shortages & 7.8 & 8 & 8 & 7 & 9 & 8 \\
\hline Ensuring contractor's cash flow & 7.8 & 8 & 8 & 7 & 8 & 8 \\
\hline Minimising social issues & 7.7 & 8 & 8 & 7 & 8 & 8 \\
\hline Handling unforeseen ground conditions & 7.6 & 8 & 7 & 7 & 8 & 7.5 \\
\hline Getting top management support & 7.4 & 8 & 8 & 7 & 8 & 7.5 \\
\hline Improving project finance from client & 7.3 & 8 & 8 & 6 & 8 & 7.5 \\
\hline Coping with low skill levels & 7.2 & 7.5 & 8 & 6 & 8 & 7.5 \\
\hline Coping with estimation errors & 7.3 & 7 & 7 & 7 & 8 & 7.5 \\
\hline Coping with legal/statutory requirements & 7.3 & 7 & 7 & 6 & 8 & 7 \\
\hline Reducing waiting time for test samples & 7 & 7 & 7 & 6 & 8 & 7 \\
\hline Handling plant shortages & 7 & 7 & 7 & 6 & 8 & 7 \\
\hline Avoiding wrong selection of plants & 6.9 & 7 & 7 & 6 & 8 & 7 \\
\hline Minimising weather uncertainties & 7.2 & 7 & 7 & 6 & 8 & 7 \\
\hline Coping with low efficiency of plants & 6.3 & 6 & 6 & 5.5 & 7 & 6.5 \\
\hline Coping with plant breakdown & 6.1 & 6 & 6 & 5 & 7 & 6 \\
\hline
\end{tabular}

${ }^{*} M=$ population central tendency

\section{Strategy and Critical Project Success Factors}

In the questionnaire survey, research participants were required to quantify the influence of strategies, on the 35 critical success factors. They were to bear in mind the projects for which the Excellence awards were made. Otherwise they could use information on other successful projects. There was an option for the participants after each category (project related, 
organizational, resource related and other) to add to the critical success factors that had not been listed. The analysis of the data received included checking its suitability, descriptive and inferential statistics to the population by using hypothesis testing. For the quantitative analysis, the SPSS 18 software package was used. The critical success factors are sorted (in Table 4) according to their population median values.

Since the variables in the analysis are abstract measures and an interval scale was used, internal reliability was considered an important pre-check before any statistical test could be performed on the data (Walliman, 2005). The 35 critical success factors together gave a Cronbach alpha value of $0.937(>0.7)$ in the reliability check using SPSS 18 . Thus, the variables were internally consistent to measure construction project implementation as a group (Malhotra et al., 2002). To ensure no influences from any project towards overall reliability, modified Cronbach alpha values were calculated by removing each response from the remaining 39 responses. The analysis found that there was no negative influence from any response. In addition to internal reliability, a missing data analysis was performed using the Little's MCAR test. For the test, the level of significance was $0.381(>0.05)$ for Chi-square $=61.665$ and 59 degrees of freedom, thus the data was considered missing randomly.

The major focus is to describe the influence of construction project strategies on critical success factors with respect to the study population. Table 4 presents the descriptive statistics the inferential statistics are based on, by using mean, median and mode as central tendencies, while percentiles (25th and 75th) are used to measure variance. The authors considered median and percentile more suitable than mean and standard deviation, because the data distributions related to the critical success factors were only normal in six cases. Descriptive statistics were used to conceptualise the population central tendencies $(\mathrm{M})$, and the values of $\mathrm{M}$ were determined through several trials. The $\mathrm{M}$ values at 95\% confidence level are based on the non-parametric alternative t-test, the Wilcoxon Signed Ranked test, which is illustrated in Table 4.

Thus, influence of construction project strategies was the highest on 'setting clear objectives' and 'handling design complexities' where the central tendencies are $M=9$. There were 12 critical success factors in which the population median value was $M=8.5$, and hence rated 'very high' according to the 10 point scale used. Among them, 'Improving schedules and plans' and 'coping with variations' are two major concerns of traditional planning algorithms such as CPM, PERT, CCPM and EVM. There were nine other factors where the population median values are $\mathrm{M}=8$. In common with the focus of traditional planning algorithms, 'ensuring feedback and monitoring' and 'ensuring contractor's cash flow' are two major concerns included among these nine factors. From the inferential statistics, the strategy-led approach had very high influence on $(\mathrm{M} \geq 8) 23$ out of $35(66 \%)$ critical factors used.

From the remaining 12 factors, the population median values are $M=7.5$; and $M=7$ for five critical success factors each. 'Improving project finance from client' belongs in the $M=7.5$ category, which is one of the major concerns that traditional planning algorithms (S-curve) focus on. The least influenced critical success factors in the population were 'coping with low efficiency of plants' $(M=6.5)$ and 'coping with plant breakdown' $(M=6)$. Nevertheless, influence on them from construction project strategies is still 'high' according to the scale used. From these findings, it could be concluded that by using the strategy-led approach, construction project managers could significantly influence all the critical success factors this study considered to be determinants of project success.

\section{Project Strategies Used to Plan and Implement Construction Projects}

This section presents the results of two consecutive stages of investigation through content analysis: the first included the open-ended questions within the questionnaire survey to NZIOB awardees, to evaluate construction project strategies they had used to successfully deliver the winning projects. The second stage involved interviews with SMEs, after the analyses of 
qualitative data gathered from the questionnaire survey. The objective was to identify construction project strategies that are used by construction project managers to plan and implement projects. The findings are presented in the following sub-headings.

\section{a) Content analysis: the questionnaire survey}

There were 82 construction project strategies mentioned in total by the NZIOB award winners in the questionnaire survey. Through content analysis, the strategies were found to comprise 58 main strategies and 24 sub-strategies. The main strategies mentioned by the participants were split between the conceptual and implementation stages, being 38 and 20 respectively. There were no identical strategies mentioned. Yet, the strategies seem to have their common focus on seven key themes, which are indicated in Table 5. These key themes include planning related, stakeholder management, construction technology, design related, visualisation, external matters related and 'other'. The key themes are used for convenience, and are not isolated. For example, to identify constraints and hence to select the most appropriate construction technology or structural design, construction project managers should have adequate understanding of a project, which could also be classified under the 'visualisation' theme.

Table 5: Distribution of themes in conceptual, implementation and sub strategies

\begin{tabular}{l|c|c|c|c|c|c|c|c}
\hline \multirow{2}{*}{ Themes identified } & \multicolumn{2}{|c|}{ Conceptual } & \multicolumn{2}{c|}{ Implementation } & \multicolumn{2}{c|}{ Sub } & \multicolumn{2}{c}{ Total } \\
\cline { 2 - 10 } & $\mathbf{N o}$ & $\mathbf{\%}$ & $\mathbf{N o}$ & $\mathbf{\%}$ & $\mathbf{N o .}$ & $\mathbf{\%}$ & No. & \% \\
\hline Visualization & 3 & 8 & 1 & 5 & 0 & 0 & 4 & 5 \\
\hline Design related & 4 & 11 & 1 & 5 & 1 & 5 & 6 & 7 \\
\hline Construction Technology & 3 & 8 & 5 & 25 & 5 & 23 & 13 & 16 \\
\hline Planning related & 18 & 50 & 5 & 25 & 6 & 27 & 29 & 35.5 \\
\hline Stakeholder management & 8 & 22 & 5 & 25 & 10 & 45 & 23 & 28 \\
\hline External matter related & 2 & 6 & 0 & 0 & 2 & 9 & 4 & 5 \\
\hline Others & 0 & 0 & 3 & 15 & 0 & 0 & 3 & 3.5 \\
\hline Total & 38 & & 20 & & 24 & & 82 & \\
\hline
\end{tabular}

From the three kinds of strategy (conceptual, implementation and sub-strategies) that the NZIOB award winners used to successfully implement their projects, the authors could categorise 35.5 per cent of them under the 'planning related' category. There were four subcategories within this theme, which are 'minimizing constraints' $(44 \%, n=8)$, 'finer planning' $(28 \%, n=5)$, 'segmental programing' $(17 \%, n=3)$ and 'collaborative planning' (11\%, $n=2)$.

From the results of the content analysis, limited resource availability is a major consideration in the NZ construction industry when planning construction projects at the conceptual stage. The precautionary strategies include 'allocating limited resources first to the critical elements of construction to minimise their influence', 'having a looking-ahead plan', 'scheduling material deliveries with program schedules while having a material buffer' and 'use of alternative construction methods to avoid completely or minimise the usage of resource constraints'. When reviewing the strategies mentioned by the awardees, their approach towards planning at the conceptual stage seemed to be proactive, as opposed to reactive, recommended in CPM algorithm. In CPM, unlimited resource availability is first assumed and then the program is adjusted through complementary analysis, such as resource balancing, to reflect resource limitations.

The second sub-theme of the 'planning-related' strategies at the conceptual stage was 'finer planning' within the activity level including assigning priorities for achievements in terms of cost, time and quality. This finding supports the argument brought by Hegazy and Menesi (2010) that the activity level is rough and inadequate when trying to plan construction projects effectively. 
However, within the limited information provided by the NZIOB awardees, there was no alignment found between conceptual strategies and the suggestions of Hegazy and Menesi (2010) given under the alternative methodology of CPM called the Critical Path Segment (CPS) method. Other conceptual level strategies related to the 'planning related' theme included segmental planning, with or without sequencing, and collaborative programming with key stakeholders, such as sub-contractors and suppliers.

When construction projects progress from the conceptual to implementation stage, the 'planning related' strategies the NZIOB award winners used, shifted focus to monitoring and adjustment procedures. The presence of out-of-scope variations due to changes in clients' desires and within-scope variations due to unforeseen conditions, and getting benefits from emerging opportunities were reasons for using strategies for monitoring and adjustment.

Sub-strategies (supportive strategies to main strategies) in the 'planning related' category include financial planning, resource balancing and risk management planning at both conceptual and implementation stages. According to Fryer (2004), strategies set for construction project implementation are trials and may not be effective, due to the dynamic nature of construction activities. In the marketing sector, only about $60 \%$ of potential strategies are effective with the effects of risks being very significant (Thompson, Strickland and Gamble, 2007). Although the context of these findings is different from the construction industry, most of the factors that cause strategy-to-implementation gaps in marketing (such as resource inadequacy and poor communication) are also critical factors to success in construction project implementation (Assaf and Al-Hejji, 2006).

The second most frequently mentioned theme was 'stakeholder management', with $28 \%$ of the strategies in total able to be categorized under this group. Regardless of the type of strategy, their aims were commonly, to share knowledge in order to clarify extremely complex situations related to design and construction methodologies, be mutually advantageous and minimise interruptions between schedules of various stakeholders under dynamic situations. In contrast, the focus of stakeholders was different in the conceptual and implementation stages. While the client was mentioned as the most dominant single stakeholder under conceptual strategies, sub-contractors, contractors' team and suppliers were more dominant stakeholders focused on during the implementation stage.

The third and fourth most frequently mentioned themes are 'construction technology' (16\%) and 'design related' (7\%), and can be considered together under value-adding techniques. These value adding techniques seem to be used to decide what should be done, how it should be done, and by which means. These are the salient activities of the CPM algorithm that need strategic thoughts (Clough, Sears and Sears, 2008). At the conceptual stage, these value adding strategies tend to eliminate uncertainties including availability of resources and consequently, schedules become more reliable during the implementation stage. The NZIOB award winners had considered value adding techniques under implementation to be included in the programme under both within and out-of-scope variations, to take advantages of emerging opportunities.

The remaining two themes were 'visualisation' and 'external matter related', both accounted for $10 \%$ of the strategies mentioned in total. Under visualisation, the focus of the conceptual implementation-level strategies was to understand construction projects better, hence to craft proactive strategies to cope with potential issues. Thus, the argument made by Abeysekera (2007) that construction project success depends on how well construction project managers can live through a project in-advance seems to be a valid conclusion. Within the information provided in the questionnaire, the authors were unable to determine which tools the NZIOB award winners had used to visualise their projects.

Under the 'external related' themes, the NZIOB awardees mentioned that strategies intended to eliminate public protests could assist in delivering their projects within goals set in terms of time, 
cost and client satisfaction. Thus, social, political and cultural issues, in which solutions are difficult to formulate by means of science and mathematics could be the ones that are important to ensure construction project success in line with Dias and Blockley (1995).

\section{b) Content analysis: the SME interviews}

From SME interviews, the complementary role of reflective practice methodologies in strategy development, to work along with traditional planning algorithms, were identified by considering a few critical success factors. Particular emphasis was paid to identifying the importance of reflective practice characteristics, which are holism, reflective interaction, context dependence and practitioner dependence (Schon, 2001), during the interviews.

The study proposition was that reflective practice methodologies could complement traditional planning algorithms during planning and implementation activities. The three SMEs agreed that both approaches are important. Throughout their involvement in project planning and implementation as construction project managers, SMEs 1, 2 and 3 quantified the average contribution of strategies crafted after reflection and traditional planning algorithm as (55:45), (50:50) and (65:35) respectively. Within the scope of this study, there was no attempt made to evaluate which is more important between reflective practice and traditional planning methodologies, hence the conclusion is limited to the fact that both are required to effectively implement construction projects to achieve successful outcomes.

On the critical success factor, 'improving schedules and plans', SME1 explained the complementary role of reflective practice methodologies to CPM/PERT algorithms. SME1 described how the uniqueness of construction technology, client requirements and the socioeconomic environment limits the use of PERT algorithm for calculating activity duration under uncertainties. SME1 emphasised that the estimation of pessimistic, optimistic and most-likely durations is difficult with the aid of historical data, due to lack of relevance to a future unique project. Further, historical data are usually kept with little or no context of the particular project environments in which the projects were implemented. Discouraging probabilistic rigours underpinned in PERT, SME1 was in favour of using tacit knowledge, which comes from past experiences and skills of professionals, to produce near-accurate estimates at the conceptual stage of projects. As opposed to mathematical equations within PERT, the estimations coming out from subjective interpretations are an outcome of visualisation, hence more reliable in planning and implementing construction projects. The acknowledgement of tacit knowledge by SME1 shows that practical solutions to real-world scenarios are practitioner-dependent, and reinforces the applicability of reflective practice.

Similar to suggestions by Lu and Lam (2008), SME1 recommended making more conservative allowances for activity duration under resource constraints. However, when project duration is limited, having conservative allowances could be a limitation, hence more holistic considerations are required to cope with multiple restraints (i.e. time and resource constraints), as opposed to reductionist methods such as adding conservative allowances. SME1 encourages the use of alternative construction methodologies and design solutions to minimise any influence from resource constraints, which are two themes that emerged from the content analysis of construction project strategies in the questionnaire survey.

The next critical success factor that was considered during the interview with SME1 was 'coping with necessary variations'. SME1 was of the view that by using the right combination of tacit knowledge and traditional planning algorithms, the quantity of time variances can be limited typically to $10-20 \%$, if no exceptional out-of-scope variations occur on projects.

SME2 opinion was sought on 'ensuring project cash flow' as a critical factor for success on construction projects. SME2 was of the opinion that the use of S-curves in cash flow forecasting has limitations when considering the New Zealand economy and client's financial capacities. 
SME2 recommended using the S-curve as a trend line only, then modifying the general solution strategically through a suitable procedure such as front-end loading, tail-end loading and middle duration loading. SME2 further recommended identifying the behaviour of the client at the conceptual stage and applying a suitable buffer between the times money is required and requested. This way, construction project managers have a higher probability of ensuring smoother cash flow when a clients' financial status become irregular. In the worst scenario, knowing of a financial interruption in advance could help the construction project manager act proactively to stop or minimise budget variances.

Finally, SME3 was more inclined towards the use of reflective practice approaches over traditional planning algorithms. According to SME3, scheduling techniques are the reasons for strategy formulation in construction projects implementation. Acknowledging the dynamic and uncertain natures of construction project environments, SME3 articulated that correct planning means creating more flexibility in schedules to implement a construction project. In SME3's own words:

"... in construction, strategies are initially formulated but they need to be flexible and changed based on situations. The project environ is constantly volatile. Better planning means more room for flexibility". Further SME3 asserts that "both norms and experience are required...; when past experience of similar scope is considered; the old rate should be modified for complexities and unforeseen situations; consider motivational factors; then calculate volume consequently duration into schedules; evaluate project total duration - apply $10 \%$ safety time - and adjust...”

The 10\% safety buffer for project durations alluded to by SME3 above, is based on past experience and could be modified as necessary. Compared to the percentage suggested in CCPM (i.e. $50 \%$ of the critical chain activities), SME3 uses a significantly low safety margin. It could be suggested that the SME3's recommendation agrees with Fallah, Ashtiani and Aryanezhad (2010) that CCPM algorithm is inappropriate due to its lack of dynamism, specifically for low risk environments.

In summary, the three interviews provided confirmation that a combination of strategies crafted after reflective practice methodologies and planning algorithms are needed to be able to cope with the complex, dynamic, uncertain and unique nature of construction projects. Construction planning and implementation require a combination of experiential/tacit knowledge for strategy formulation, and planning algorithms. Thus the study's postulation of a strategy-led approach to successful planning and implementation of construction projects seem confirmed.

\section{Why the strategy-led approach is suitable and will cope with project characteristics}

This part of the study describes a quantitative evaluation to confirm that strategies, crafted in line with reflective practice methodologies can minimise the drawbacks of traditional planning algorithms. A correlation analysis using SPSS 18 is undertaken from data collected from the NZIOB awardees. The null and alternative hypotheses developed for the analysis are as follows:

H0: There is no significant linear correlation between the influence of strategies for project implementation and four project characteristics: complexity, dynamism, uncertainty and uniqueness $(\mathrm{r}=0)$

H1: There is a significant linear relationship between the influence of strategies for project implementation and the four project characteristics: complexity, dynamism, uncertainty and uniqueness $(r \neq 0)$

To simulate the impact of construction project strategies on construction project planning and implementation, the authors used the influence of strategies towards the 35 critical success 
factors, which were summarised in Table 2. The NZIOB awardees had indicated the amount of complexity, dynamism, uncertainty and uniqueness on a scale of 0 to $100(0-20$ being very low and 80-100 being very high) for the projects they selected and implemented through the strategyled approach.

Table 6 gives both descriptive and inferential statistics related to the variables, the characteristics of construction projects. According to the Shapiro-Wilk test, the data distributions of the four variables were normal; hence the authors selected mean values as the most appropriate measure of central tendency. In the sample representing the projects for which the NZIOB awards were made, complexity and uniqueness had the highest and the second highest mean values; which are 79 and 77, respectively. Dynamism and uncertainty had mean values of 73 and 67 respectively. Since the research participants' perceptions of complexity are above 60 for all the data entities, the construction projects in the sample had at least one project characteristic rated highly or very highly influenced by their technological and managerial contexts. There was no project entity in the sample where the characteristics were rated 'low' or 'very low', except in the case of uncertainty, where an outlier equal to 20 was present. The last column in Table 6 shows that each characteristic of the population had mean values within the 'high' region of the scale used.

Table 6: Descriptive/inferential statistics of the project characteristics

\begin{tabular}{l|c|c|c|c|c}
\hline \multirow{2}{*}{ Variable } & \multicolumn{4}{c|}{ Sample } & Population \\
\cline { 2 - 6 } & Minimum & Maximum & Mean & Std. Deviation & mean $\mu$ \\
\hline Complexity & 60.00 & 100.00 & 79 & 10 & 75 \\
\hline Dynamism & 45.00 & 100.00 & 73 & 13 & 65 \\
\hline Uncertainty & 20.00 & 95.00 & 68 & 13 & 60 \\
\hline Uniqueness & 40.00 & 95.00 & 77 & 11 & 70 \\
\hline
\end{tabular}

Since the data distributions of the influence of the strategies on the critical success factors were non-normal, non-parametric Spearman correlation was the most appropriate statistical tool to measure the linear relationships between the two types of variables (Malhotra et al., 2002). Table 7 shows the significant relationships established between the project characteristics and the influence of strategies from the statistical analysis at $\alpha=0.05$ significance level.

On the results presented in Table 7, complexity showed significant positive correlation at $\alpha=0.05$ with nine variables. Complexity had the highest correlation with 'improve schedules and plans', which was $r=0.719$. This correlation was followed by 'better handling design complexities' having a Spearman correlation value of $\mathrm{r}=0.496$. Having the highest and second non-parametric correlations towards 'coping with necessary variations' $(\mathrm{r}=0.627)$ and 'ensuring feedback and monitoring' $(r=0.511)$, dynamism showed statistically significant relationships at $\alpha=0.05$ significance, with 10 out of the 35 critical success factors. Similarly, uncertainty had 10 significant relationships according to the correlation analysis, where the highest correlation was with 'minimising economic issues' (0.512). Uniqueness showed the least number of correlations with the critical success factors, which were seven in total. The highest and the second highest correlations were with 'effective use of technology' $(r=0.557)$ and 'improve schedules and plans' $(\mathrm{r}=0.542)$, respectively.

As a summary to the correlation analysis, 20 out of 35 variables $(57 \%)$ related to the influence of strategies towards critical success factors, correlated with at least one of the project characteristics at $\alpha=0.05$ significance level. This implies that strategies have an influence on project planning and implementation within the context of construction project characteristics (complexity, dynamism, uncertainty and uniqueness). 
Table 7: Spearman correlations between the project characteristics and the influence of strategies toward critical success factors

\begin{tabular}{|c|c|c|c|c|}
\hline \multirow{2}{*}{ Strategy influence on success factors } & \multicolumn{4}{|c|}{ Inference to H16 } \\
\hline & Complexity & Dynamism & Uncertainty & Uniqueness \\
\hline Coping with necessary variations & $\mathrm{r}=0.358$ & $\mathrm{r}=0.627$ & $\mathrm{r}=0.366$ & Not supported \\
\hline Speeding up decision making & Not supported & Not supported & $\mathrm{r}=0.332$ & Not supported \\
\hline Handling unforeseen ground conditions & Not supported & Not supported & $\mathrm{r}=0.344$ & Not supported \\
\hline Improving schedules and plans & $\mathrm{r}=0.719$ & Not supported & $\mathrm{r}=0.346$ & $\mathrm{r}=0.542$ \\
\hline Coping with legal/statutory requirements & $\mathrm{r}=0.327$ & Not supported & Not supported & Not supported \\
\hline Ensuring feedback and monitoring & Not supported & $\mathrm{r}=0.511$ & $\mathrm{r}=0.384$ & Not supported \\
\hline Better handling of design complexities & $\mathrm{r}=0.496$ & $\mathrm{r}=0.380$ & $\mathrm{r}=0.336$ & Not supported \\
\hline Coping with estimation errors & Not supported & $\mathrm{r}=0.379$ & $\mathrm{r}=0.377$ & $\mathrm{r}=0.509$ \\
\hline Effective use of technology & Not supported & Not supported & Not supported & $\mathrm{r}=0.557$ \\
\hline Dealing with client characteristics & $\mathrm{r}=0.333$ & $\mathrm{r}=0.388$ & $\mathrm{r}=0.436$ & Not supported \\
\hline Improving project finance from client & Not supported & $\mathrm{r}=0.472$ & Not supported & Not supported \\
\hline Getting top management support & Not supported & $\mathrm{r}=0.384$ & Not supported & $\mathrm{r}=0.539$ \\
\hline Developing project organisational structure & Not supported & $\mathrm{r}=0.322$ & Not supported & Supported \\
\hline Getting lower cadre support & Not supported & Not supported & Not supported & $r=.0443$ \\
\hline Minimising material shortages & $\mathrm{r}=0.328$ & Not supported & Not supported & Not supported \\
\hline Coping with low skill levels & $\mathrm{r}=0.398$ & Not supported & Not supported & Not supported \\
\hline Handling plant shortages & Not supported & Not supported & $\mathrm{r}=0.363$ & Not supported \\
\hline Minimising political issues & $\mathrm{r}=0.466$ & $\mathrm{r}=0.336$ & Supported & $\mathrm{r}=0.509$ \\
\hline Minimising economic issues & Not supported & $\mathrm{r}=0.372$ & $\mathrm{r}=0.512$ & $\mathrm{r}=0.328$ \\
\hline Minimising social issues & $\mathrm{r}=0.466$ & Not supported & Not supported & Not supported \\
\hline
\end{tabular}

\section{Discussion}

This study provides empirical evidence, that the strategy-led approach could holistically influence the functions of construction project planning and implementation. The 40 projects used in this study were recognised widely in the New Zealand construction industry as delivered with excellent performances. From the qualitative information, success was also widely attributed to the strategies adopted by the project managers. Thus the strategy-led approach could be considered as a viable planning methodology to achieve successful project delivery.

Further, the SMEs emphasised the importance of using both strategies and traditional planning algorithms, complementarily. As previously explained, deficiencies of the traditional planning algorithms are due to their underpinnings which are basically in statistics and other mathematical techniques. These algorithms provide general solutions to construction project planning while neglecting the essence of subjective knowledge (practitioner independency) and effect from the project characteristics (context independency) (Long and Ohsato, 2007). Further, these mathematical rigours have minimum ability in clarifying qualitative features and finding solutions to them (Kinsella, 2007). Qualitative features, such as organizational, social, cultural and political environments, could be the ones that largely govern project success and make project planning and implementation challenging, including the decisions on right technologies (Dias, 2002; Azhar, Khalfan and Maqsood, 2012).

One of the critical success factors this study considered for in-depth evaluation using the SME interviews was 'developing planning schedules'. This critical success factor is influenced to very high degree (the population median tendency, $\mathrm{M}=8.5$ ) by project strategies crafted by the participants. The correlations between 'strategies influence towards improving schedules and plans' (S) and the project characteristics are statistical significant. Complexity, uncertainty and 
uniqueness govern $51 \%\left(\mathrm{r}^{2}\right), 12 \%$ and $29 \%$ of the variances experienced in $\mathrm{S}$, respectively. This indicates that strategies should be used thoroughly under scheduling and planning, though the traditional planning algorithms are widely used.

According to the SMEs, traditional methodologies (such as activity estimates and variations), should be embedded within the context of strategies using subjective interpretations. These follow similar suggestions in strategy literature (Wong and Ng, 2010; Betts and Ofori, 1992). Due to the unique nature of construction projects, historical data can become less meaningful or meaningless at worst, if the relevant context is unknown. Cottrell (1999) provides this criticism of the applicability of the PERT algorithm, that having three points estimates (pessimistic, optimistic and most-likely duration), is ambiguous for each and every activity. Advancements to the traditional planning algorithms in literature do not consider the requirement for generalspecific relationships and focus only on changing mathematical assumptions (for example: deriving equations by assuming alternative probability density functions) (Cottrell, 1999; Zhao, You and Zuo, 2010). Therefore the findings of this study, along with the suggestions in literature, justify the limitations of the principles of classical statistics to cope with uncertainties in real-world scenarios.

Hegazy and Menesi (2010) suggested adding buffers as a strategy to 'cope with variations', which is another critical success factor this study considered. According to the study findings, construction project managers use different strategies from adding buffers in real practice. Using effective construction methodologies, pragmatic design solutions and distinct calendars between planning and implementation are some the most favourable strategies the NZIOB award recipient mentioned. These strategies could ensure positive improvements towards the critical success factor, which the median central tendency was quantified to be $M=8.5$ (very high influence). One may argue that the latter option, the use of different calendars for planning and implementation, is also buffering. In practice, in this strategy, non-working days are used under unavoidable variations as a virtue of necessity. Thus, it does not add a redundant capacity to schedules at the early-stage, as opposed to in-built buffers that are characterised by the 'student syndrome' (i.e. the tendency in humans to leave work to the last moment) (Lee, Pena-Mora and Park, 2006). In this way, construction project strategies seem to consider multiple requirements of construction project implementation, such as achievements in terms of cost and time, in a holistic way. Thus, the strategy-led approach that the NZIOB award recipients used in planning and implementation of their construction projects is quite different from traditional planning algorithms, which are reductionist (Lu and Lam, 2008).

Widely-used planning algorithms in construction project planning (e.g. CPM, PERT, CCPM and EVM) consider decision making to be straightforward procedures (Long and Ohsato, 2007). Thus, the algorithms are based on Hard Systems Methodology (Checkland and Scholes, 1990). Together with literature (e.g. Dias, 2002), the findings of this study indicate that problem solving and providing appropriate solutions are fuzzy in reality due to the unique characteristics of construction projects. Dias and Blockley (1995) acknowledged that engineering theories based on Hard Systems Methodology could work, for centuries to solve problems. However, with the emergence of Gödel's incompleteness theorems and Heisenberg's uncertainty principle, inadequacies of the Hard Systems Methodology were identified. Hence an alternative paradigm, the Soft System Methodology, was suggested to clarify issues related to complex and uncertain situations (Dias, 2002). The Soft System Methodology encourages the practitioner to experiment in decision making via reflection in, on and for action. This study believes that models can be formulated to clarify the strategy-led approach by using the principles of Soft Systems Methodology. However future study is required to systematically corroborate facts to this assumption. 


\section{Conclusion}

This study encourages industry practitioners to use the strategy-led approach to effectively plan and implement construction projects. The-strategy led approach encourages reflective practice (experiential/tacit knowledge) approaches to develop project strategies during planning and implementation activities on construction projects. Reflective knowledge complements traditional planning algorithms for more reliable project outcomes. Traditional planning algorithms use historical data with little or no concern for contextual backgrounds, hence can give misleading estimates, which eventually lead to cost and time overruns, and quality issues. Real-world construction project scenarios are complex, dynamic, uncertain and unique; hence neither problems nor solutions are straightforward. Thus, the study contends that academic solutions to construction project planning problems should encourage practitioners to become experimental i.e. reflective practitioners. By considering these facts, the authors recommend developing potential strategy models to planning and implementation of construction projects by using the underpinnings of the Soft Systems Methodology.

Readers should be aware that there are limitations of this study. One of them is the inability of the study to meet the required sample size $(n=69)$, to achieve the $95 \%$ confidence level required under inferential statistical analysis. The actual response rate was 58\% ( $\mathrm{n}=40)$ thus the generalisation of the findings would need to be approached with caution. Further, due to the context-dependent nature of construction projects, the determinants of construction project success and strategies that are applicable to other project environments can vary. However, reliability of this study is assured because the study has been based on critical multiplism, where the findings of the archival analysis, questionnaire survey and SME interviews are triangulated.

To investigate the suitability of a strategy-led approach to influence critical success factors, this study used only successful construction projects which were recognised in the New Zealand industry. Thus, project failures and negative influences towards critical success factors due to the use of construction project strategies were redundant within the scope of this study. To extend the findings of this study, future study will be required to evaluate the potential consequences of the strategy-led approach. Further, complexity, dynamism, uncertainty and uniqueness are considered to be the construction project characteristics that make traditional planning algorithms inadequate. Thus, other characteristics that can make construction project planning difficult, such as responsiveness or the susceptibility of projects to environmental dynamics, were not considered in this study.

\section{Acknowledgements}

The authors would like to acknowledge the Faculty of Design and Creative Technologies, Auckland University of Technology for funding this short-term postdoctoral fellowship study.

\section{References}

Abbott, D., 2010. Sociology Revision - Methodology, Positivism and Interpretivism. [online] Available at: <http://tutor2u.net/blog/index.php/sociology/comments/sociology-revision-methodology-positivism-andinterpretivism> [accessed 31 March 2012].

Abeysekera, V., 2007. Living through a Project: A Strategy-Led Approach for Project Success. Construction information quarterly, 9(4), pp.186-91.

AIA, 2007. Integrated Project Delivery: A Guide. CA: The American Institute of Architects.

Arashpour, M., Wakefield, R., Blismas, N. and Leeb, E.W.M., 2014. Framework for improving workflow stability: deployment of optimized capacity buffers in a synchronized construction production. Canadian Journal of Civil Engineering, 41(12), pp.995-1004. doi: http://dx.doi.org/10.1139/cjce-2014-0199

Assaf, S.A. and Al-Hejji, S., 2006. Causes of delay in large construction projects. International Journal of Project Management, 24(4), pp.349-57. doi: http://dx.doi.org/10.1016/i.ijproman.2005.11.010 
Azhar, S., Khalfan, M. and Maqsood, T., 2012. Building information modelling (BIM): now and beyond. Australasian Journal of Construction Economics and Building, 12(4), pp.15-28. doi: http://dx.doi.org/10.5130/ajceb.v12i4.3032

Barribeau, P., Butler, B., Corney, J., Doney, M., Gault, J., Gordon, J., Fetze, R., Klein, A., Rogers, C.A., Stein, I.F., Steiner, C., Heather, U., Waggoner, T. and Palmquist, M., 2012. Pretesting the Questionnaire. [online] Available at: http://writing.colostate.edu/guides/research/survey/com4a3.cfm [Accessed 02 March 2012].

Bartlett, J.E., Kotrlik, J.W. and Higgins, C.C., 2001. Organizational Research: Determining Appropriate Sample Size in Survey Research. Information Technology, Learning, and Performance Journal, 19(1), pp.43-50.

Beck, P., 2005. Collaboration vs. Integration: Implications of a Knowledge-Based Future for the AEC Industry. GA: Design Intelligence Design Futures Council.

Belassi, W. and Tukel, O.I., 1996. A new framework for determining critical success/failure factors in projects. International Journal of Project Management, 14(3), pp.141-51. doi: http://dx.doi.org/10.1016/0263-7863(95)00064-X

Betts, M. and Ofori, G., 1992. Strategic planning for competitive advantage in construction. Construction Management and Economics, 10(6), pp. 511-32. doi: http://dx.doi.org/10.1080/01446199200000049

Chan, D.W.M. and Kumaraswamy, M.M., 1997. A comparative study of causes of time overruns in Hong Kong construction projects. International Journal of Project Management, 15(1), pp.55-63. doi: http://dx.doi.org/10.1016/S0263-7863(96)00039-7

Checkland, P.B. and Scholes, J., 1990. Soft System Methodology in Action. Chichester: John Wiley \& Sons.

Clough, R.H., Sears, G.A. and Sears, S.K., 2008. Construction Project Management. 5th ed. New Jersey: John Wiley \& Sons.

Cottrell, W.D., 1999. Simplified Program Evaluation and Review Technique. Journal of Construction Engineering and Management, 125(1), pp.16-22. doi: http://dx.doi.org/10.1061/(ASCE)0733-9364(1999)125:1(16)

De Wit, B. and Meyer, R., 2004. Strategy: Process, Content, Context. London: Thomas Learning.

Dias, W.P.S., 2002. Reflective practice, artificial intelligence, and engineering design: Common trends and interrelationships. Artificial Intelligence for Engineering Design, Analysis and Manufacturing, 16(4), pp.261-71. doi: http://dx.doi.org/10.1017/S0890060402164018

Dias, W.P.S. and Blockley, D.I., 1995. Reflective practice in engineering design. ICE Proceedings on Civil Engineering, 108(4), pp.160-68. doi: http://dx.doi.org/10.1680/icien.1995.28038

El-Anwar, O. and Aziz, T.A., 2014. Integrated Urban-Construction Planning Framework for Slum Upgrading Projects. Journal of Construction Engineering Management, 140(4), B4014003. doi: http://dx.doi.org/10.1061/(ASCE)CO.1943-7862.0000684

Fallah, M., Ashtiani, B. and Aryanezhad, M.B., 2010. Critical Chain Project Scheduling: Utilizing uncertainty for Buffer Sizing. International Journal of Research and Review for Applied Science, 3(3), pp.280-83.

Fryer, B., 2004. The practice of construction management. Oxford: Blackwell Publishing.

Grant, M.G. and Giddings, L.S., 2002. Making sense of methodologies: A paradigm framework for the novice researcher. Contemporary Nurse, 13(1), pp.10-28. doi: http://dx.doi.org/10.5172/conu.13.1.10

Griloa, A. and Jardim-Goncalves, R., 2011. Challenging electronic procurement in the AEC sector: A BIM-based integrated perspective. Automation in Construction, 20(2), pp.104-14. doi: http://dx.doi.org/10.1016/j.autcon.2010.09.008

Guba, E.G. and Lincoln, Y.S., 2005. The Sage Handbook of Qualitative Research. 3rd ed. Thousand Oaks: SAGE.

Hardy, J.V., 1970. Cash flow forecasting for the construction industry. MSc. Loughborough University of Technology.

Hegazy, T. and Menesi, W., 2010. Critical Path Segments Scheduling Technique. Journal of Construction Engineering and Management, 136(10), pp. 1078-85. doi: http://dx.doi.org/10.1061/(ASCE)CO.1943-7862.0000212

Kinsella, E.A., 2007. Technical rationality in Schön's reflective practice: dichotomous or non-dualistic epistemological position. Nursing Philosophy, 8(2), pp.102-13. http://dx.doi.org/10.1111/j.1466769X.2007.00304.x

Kumar, D., 2002. Developing strategies and philosophies early for successful project implementation. International Journal of Project Management, 7(3), pp.164-71. doi: http://dx.doi.org/10.1016/0263-7863(89)90035-5

Kumaraswamy, M.M. and Chan, D.W.M., 2002. Compressing construction durations: lessons learned from Hong Kong construction projects. International Journal of Project Management, 20(1), pp.23-35. doi: http://dx.doi.org/10.1016/S0263-7863(00)00032-6

Kumaraswamy, M.M. and Chan, W.M., 1998. Contributors to construction delays. Construction Management and Economics, 16(1), pp.17-29. doi: http://dx.doi.org/10.1080/014461998372556

Lee, S., Peña-Mora, F. and Park, M., 2006. Reliability and Stability Buffering Approach: Focusing on the Issues of Errors and Changes in Concurrent Design and Construction Projects. Journal of Construction Engineering and Management, 132(5), pp.452-64. doi: http://dx.doi.org/10.1061/(ASCE)0733-9364(2006)132:5(452)

Long, L.D. and Ohsato, A., 2007. Fuzzy critical chain method for project scheduling under resource constraints and uncertainty. International Journal of Project Management, 26(6), pp.688-98. doi: http://dx.doi.org/10.1016/j.ijproman.2007.09.012

Lu, M. and Lam, H-C., 2008. Critical Path Scheduling under Resource Calendar Constraints. Journal of Construction Engineering and Management, 134(1), pp.25-30. doi: http://dx.doi.org/10.1061/(ASCE)0733-9364(2008)134:1(25)

Malhotra, N., Hall, J., Shaw, M. and Oppenheim, P., 2002. Market research: An applied orientation. NSW: Prentice Hall. 
Menesi, W., 2010. Construction Scheduling Using Critical Path Analysis with Separate Time Segments. PhD. University of Waterloo.

Pinto, J.K. and Covin, J.G., 1989. Critical factors in project implementation: A comparison of construction and R\&D projects. Technovation, 9(1), pp.49-62. doi: http://dx.doi.org/10.1016/0166-4972(89)90040-0

Ramanayaka, C., 2013. Developing a strategy-led approach as a methodology to plan and implement construction projects. $\mathrm{PhD}$. Auckland University of Technology.

Ramanayaka, C. and Rotimi. J., 2011. Strategy: Towards its applicability for successful project delivery. In: Egbu, C., and Lou, E.C.W. The 27th ARCOM. Bristol, 5-7 September 2011. ARCOM: Bristol.

Ramanayaka, C. and Rotimi. J., 2012. Strategy-led Construction: Success Through a Human-Centred Approach. In: Kamardeen, I., Newton, S., Lim, B. and Loosemore, M. The 37th Annual Conference of AUBEA, Sydney, 4-6 July 2012. AUBEA: Sydney.

Rand, G.K., 2000. Critical chain: the theory of constraints applied to project management. International Journal of Project Management, 18(3), pp.173-77. doi: http://dx.doi.org/10.1016/S0263-7863(99)00019-8

Schlomer, G. L., Bauman, S., and Card, N. A., 2010. Best Practices for Missing Data Management in Counselling Psychology. Journal of Counselling Psychology, 57(1), pp. 1-10. doi: http://dx.doi.org/10.1037/a0018082

Schon, D., 2001. The Crisis of Professional Knowledge and the Pursuit of an Epistemology of Practice. In: J. Raven and J. Stephenson, eds. 2001. Competence in the Learning Society. NY: Peter Lang. Ch 13.

Shim, E. and Kim, S., 2011. The Cash-flow Simulation Game: Introduction. In: El-Gafy, M. ASC Region III Conference. Illinois, 26-29 October 2011. Illinois: Downers Grove.

Thompson, A.A., Strickland, A.J. and Gamble, J.E., 2007. Crafting and executing strategy: The quest for competitive advantage. Boston: McGraw-Hill.

Vilasini, N., Neitzert, T. and Rotimi, J.O.B., 2014. Developing and evaluating a framework for process improvement in an alliance project: a New Zealand case study. Construction Management and Economics, 32(6), pp.625-40. doi: http://dx.doi.org/10.1080/01446193.2013.874565

Walliman, N., 2005. Your Research Project: a step-by-step guide for the first-time researcher. Thousand Oak: SAGE.

Wang, H., Shen, Q., Tang, B-S., Lu, C., Peng, Y. and Tang, L., 2014. A framework of decision-making factors and supporting information for facilitating sustainable site planning in urban renewal projects. Cities, 40, pp.44-55. doi: http://dx.doi.org/10.1016/i.cities.2014.04.005

Winch, G.M., 2010. Managing Construction Projects. Singapore: Blackwell Publishing.

Wong, J.M.W. and Ng, T.S., 2010. Company Failure in the Construction Industry: A Critical Review and a Future Research Agenda. In: FIG, Proceedings of the FIG Congress. Sydney, 11-16 April 2010. Sydney: FIG.

Zhao, Z.Y., You, W.Y. and Zuo, J., 2010. Application of Innovative Critical Chain Method for Project Planning and Control under Resource Constraints and Uncertainty. Journal of Construction Engineering and Management, 136(9), pp.1056-60. doi: http://dx.doi.org/10.1061/(ASCE)CO.1943-7862.0000209 